\title{
Sipper (Sistem Informasi Peminjaman Perpustakaan) Berbasis Barcode
}

\author{
Regita Cahya Pramesti ${ }^{1}$, Endah Sudarmilah ${ }^{2}$ \\ ${ }^{1,2)}$ Program Studi Informatika,Universitas Muhammadiyah Surakarta

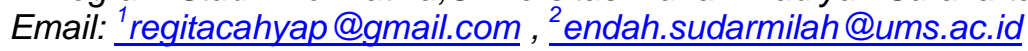

(Naskah masuk: 21 Oktober 2019, diterima untuk diterbitkan: 4 November 2019)

\begin{abstract}
ABSTRAK
Perpustakaan merupakan sebuah institusi yang menyimpan dan mengolah karya ilmiah untuk memenuhi kebutuhan intelektualitas para penggunanya untuk keperluan pendidikan, penelitian dan kebutuhan lain. Selain kegunaannya dalam dunia keilmuan, perpustakaan sendiri akan lebih baik jika memiliki fasilitas yang dapat memudahkan petugas dan anggota dalam proses peminjaman, pengembalian serta pencarian buku, ditambah dengan sistem transparansi transaksi dan denda diharapkan dapat membuat sistem ini menjadi lebih baik. Tujuan penelitian kali ini untuk merancang bangun sistem dengan memanfaatkan Barcode scanner agar proses peminjaman lebih cepat, akurat, efektif dan efisien serta untuk meminimalisir kesalahan dalam pengetikan saat proses transaksi peminjaman dan pengembalian buku. Metode yang dipakai dalam merancang dan membangun sistem ini adalah metode waterfall. Media untuk menyimpan data-data mengenai perpustakaan disimpan dalam database MySql (PhpMyAdmin) dan menggunakan arsitektur framework Codelgniter. Hasil yang diharapkan, sistem dapat memberikan kemudahan bagi petugas dalam mengelola setiap aktivitas mengenai perpustakaan dan juga anggota mudah dalam mencari buku yang ingin dipinjam serta dapat terjadinya transparasi denda dan transaksi.
\end{abstract}

Kata kunci: barcode, waterfall, framework codeigniter

\begin{abstract}
The library is a place that stores and processes scientific work to meet the intellectual needs of its users for educational, research and other needs. In addition to its use in the scientific world, the library itself will be better if it has facilities that can facilitate officers and members in the loan process, facilitate and search for books, plus a system that supports transactions and data that can make this system better. The purpose of this study is to improve the system by utilizing a Barcode scanner so that the loan process is faster, more accurate, effective and efficient and to minimize errors in typing during the loan transaction and book purchase process. The method used in the development and manufacture of this system is the waterfall method. The media for storing data about library storage in a MySql (PhpMyAdmin) database and using the Codelgniter framework architecture. Expected results, the system can make it easy for officers in every activity regarding the library and also members who are easy to find books to borrow and can use transparency and transaction transparency.
\end{abstract}

Keywords: barcode, waterfall, framework codeigniter

\section{PENDAHULUAN}

Layanan informasi terus berkembang seiring dengan perubahan zaman, hal tersebut juga terjadi pada perpustakaan yang telah memulai jalan model, dan secara bertahap mengembangkan karakteristik disiplin diri
(Zhang, 2019). Perpustakaan merupakan sebuah lembaga yang menjadi tempat penyimpanan dan pengelolahan berbagai macam koleksi. Koleksi yang dimaksud adalah jumlah total semua bahan yang membentuk kepemilikan perpustakaan yang mencakup buku, dokumen, disertasi, atlas dan bahan non-buku seperti slide, 
gambar dan lain-lain(Okolo, Eserada, Ugboh, \& Ngbo, 2019).

Banyaknya koleksi yang dimiliki perpustakaan harus dikelola secara baik agar dapat memberikan kemudahan dan manfaat yang lebih kepada anggota dan petugas dalam mendapatkan informasi yang cepat, akurat dan tidak terjadi kekeliruan. Setidaknya ada empat bidang yang menjadi tugas perpustakaan, yaitu kurasi yang meliputi pemilihan, pengumpulan, pemeliharaan, penyimpanan, dan pemberian akses informasi; berperan dalam pembelajaran dan penelitian; berperan dalam publikasi; menciptakan dan mengelola tempat untuk sumber informasi bagi pengguna(Kurniasih et al., 2019). Beberapa kendala seperti petugas yang kesulitan dalam mengelola serta memantau data peminjaman, pengembalian dan juga anggota yang kesulitan mengakses informasi tentang ketersediaan buku dapat terjadi, jika pengelolahan data dilakukan masih manual.

Membangun sebuah sistem informasi perpustakaan dengan sistem web base dapat menjadi salah satu alternatif untuk membantu petugas dalam menyelesaikan kendala-kendala yang terjadi(Hendrianto, 2014). Terlebih lagi sekarang ini karena perkembangan teknologi semakin pesat, semua instansi dituntut harus mengupayakan peranan teknologi dari berbagai segi, salah satunya segi pelayanan guna meningkatkan kualitas dari kerja yang dilakukan, dan keakuratan dalam penyajian informasinya(Sukrianto \& Oktarina, 2017). Sistem web base tersebut membuat anggota dan petugas menjadi tidak memiliki batasan waktu, tempat dan biaya untuk mengakses informasi mengenai perpustakaan(Ridha, 2017). Informasi yang disajikan dari sistem web base pun dapat berubah seiring waktu dan selalu up to date(Firman, Wowor, \&
Najoan, 2016). Penulis bermaksud untuk membuat sistem informasi peminjaman buku perpustakaan dengan memanfaatkan barcode serta menggunakan kerangka kerja PHP codeigniter. Dipilinnya barcode karena merupakan teknologi pengkodean yang menyimpan data waktu nyata, dimana umumnya digambarkan sebagai kumpulan pola bar berwarna hitam dengan spasi putih. Kemampuan barcode yang dapat membaca informasi 3 kali lebih cepat cocok untuk karya berulang. Perpustakaan menjadi contoh yang sempurna untuk karya berulang, terutama di counter sirkulasi, untuk mengurangi kesalahan pengetikan saat proses peminjaman buku(Rahaman, 2016). Sistem yang akan dibuat juga menggunakan kerangka kerja PHP codeigniter. Ada beberapa alasan mengapa memilih kerangka kerja PHP, terutama karena mereka menawarkan kemampuan untuk membuat aplikasi web yang lebih kompleks dengan struktur file yang mudah digunakan, aman dan lengkap lebih cepat daripada sebelumnya. (Benmoussa, Laaziri, Khoulji, Larbi, \& El Yamami, 2019). Penelitian yang dilakukan (Heriyanto, Kurniawan, \& Taufik, 2017) menjelaskan bahwa karakteristik yang dimiliki codeigniter yaitu menggunakan pola Model, View, dan Controller (MVC) yang membantu pengembang untuk mengerjakan aplikasi lebih cepat daripada menulis semua kode dari nol, serta struktur kode yang dihasilkan juga lebih terstruktur dan memiliki standar yang jelas. Arsitektur MVC yang dimiliki codeigniter diharapkan dapat menghasilkan sistem peminjaman buku perpustakaan yang lebih efisien, sehingga pustakawan nantinya dapat lebih mudah mengelola informasi perpustakaan dan pengembang dapat lebih mudah dalam pengembangan sistem (Wiharto, 2016). Hasil dari sistem diharapkan dapat membantu petugas dalam menangani aktivitas di perpustakaan dan juga 
memberikan kemudahan bagi anggota dalam melakukan pencarian buku, melihat transparansi denda dan transaksi yang pernah dilakukan.

\section{METODE}

Metode penelitian yang dilakukan dalam membangun sistem ini diawali dengan observasi, kemudian wawancara kepada petugas perpustakaan di SMP Batik Surakarta untuk mendapatkan analisis kebutuhan, dilanjutkan dengan perancangan menggunakan metode System Development Life Cycle(SDLC) dengan model waterfalldengan memanfaatkan UML (unified modelling language) yang terdiri dari use case diagram, class diagram dan activity diagram(Puspaningrum \& Sudarmilah, 2020). Metode SDLC waterfall merupakan metode klasik, tetapi masih sering digunakan dalam metode penelitian karena terstruktur secara sistematis dari fase sebelum mulai hingga fase setelah sistem informasi selesai(Choiyanti, Latifah, \& Triyanto, 2020). Mengimplementasikan model waterfall terdapat prosedur development yang harus dijabarkan agar sebuah sistem dapat tercipta dengan baik(Malau, Salim, Santoso, \& Ramadan, 2018). Detail dari metode waterfalldapat dilihat dalam Gambar 1.

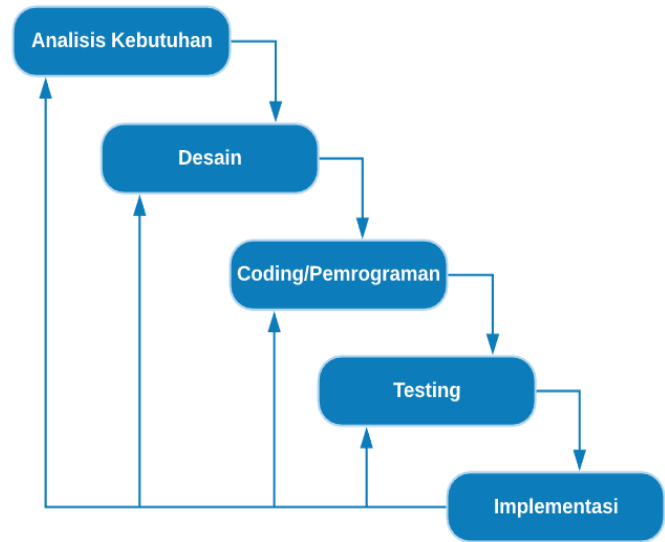

Gambar 1. Metode SDLC(Waterfall)

Tahapan dalam metode Waterfall :
1. Analisis Kebutuhan

Tahapan ini merupakan proses analisis terhadap data yang telah dikumpulkan yang sesuai dengan integrasi sistem(Pratiwi, Hartini, \& Marlina, 2018). Kebutuhan non-fungsional dalam penelitian kali ini mengenai hardware dan software yang di gunakan, sebagai berikut :

a. Non-Fungsional :

Tabel 1 Kebutuhan Non Fungsional.

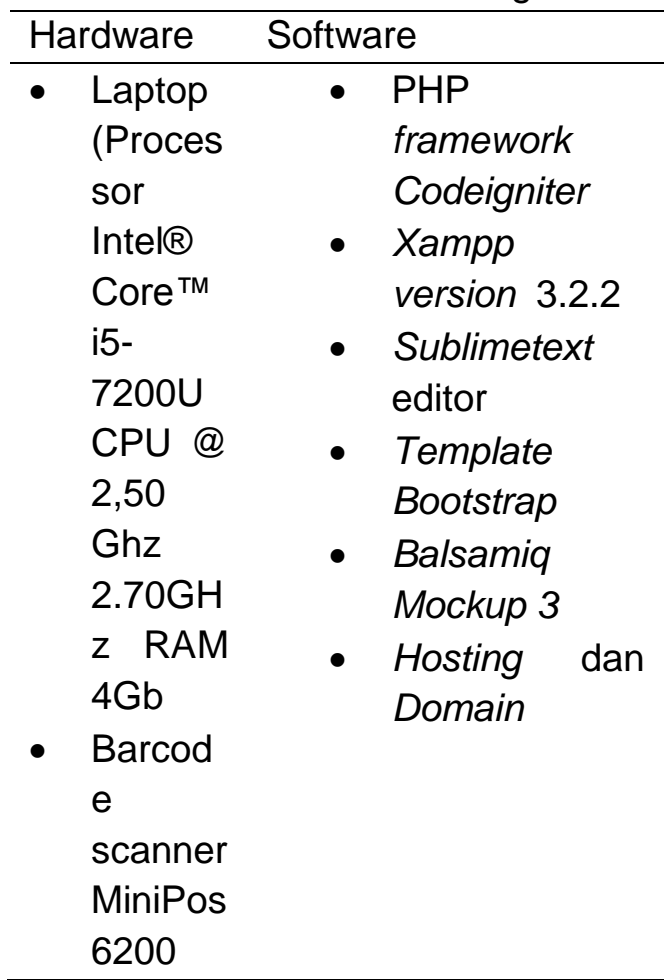

b. Fungsional :

1. Admin / Petugas Perpustakaan :

- Melakukan Login

- Mengatur Transaksi Peminjaman dan Pengembalian

- Mengelola Data Buku

- Mengelola Data Anggota

- Mengelola Data Petugas

- Mengelola Data Penerbit

- Mengelola Data Pengarang

- Kalkulasi Denda

2. Anggota :

- Melakukan Pencarian Buku

- Cek Transaksi dan Denda

2. Desain Sistem/Perancangan 


$\begin{array}{crll}\begin{array}{c}\text { Tahap selanjutnya } \\ \text { desaitu }\end{array} & \begin{array}{l}\text { pencarian buku dan melakukan } \\ \text { sistem. }\end{array} & \begin{array}{l}\text { pengecekan terhadap transaksi yang } \\ \text { pernah dilakukan, serta untuk cek denda }\end{array} \\ \text { Menggambarkan alur proses yang terjadi } & \text { penan }\end{array}$
merupakan tujuan dari perancangan sistem(Rita Irviani, 2017).

a. Desain Basis Data

Desain basis data digunakan untuk menggambarkan hubungan atau relasi antar data(Febi Andrea Renatha, Kodrat Iman Satoto, 2015). Basis data yang terdapat dalam Gambar 2 merupakan gambaran basis data fisik. Rancangan basis data ini, kemudian akan diimplementasikan kedalam mysql. Mysql menggunakan Bahasa Structured Query Language(SQL) dan merupakan multiuser database(Putera \& Ibrahim, 2018).

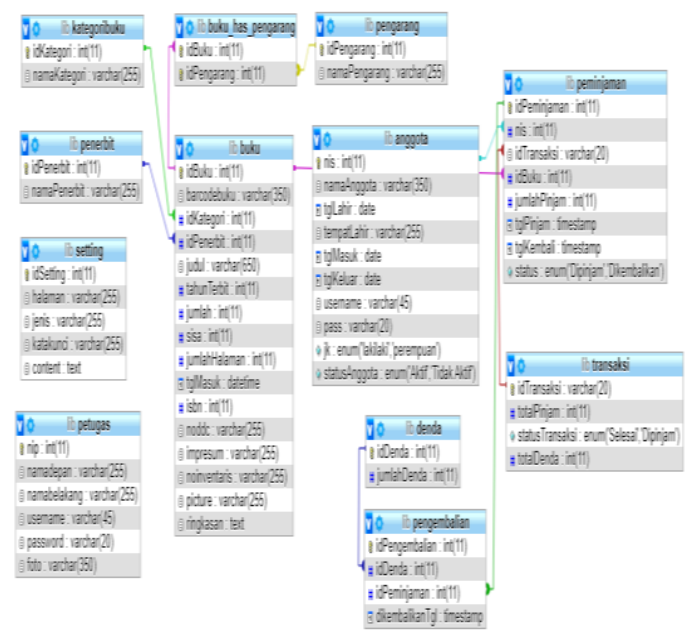

Gambar 2. ERDiagram b. Use Case Diagram

Sistem aplikasi perpustakaan ini dapat digambarkan pada use casediagram seperti Gambar 3.Use case diagram akan menjelaskan gambaran interaksi yang terjadi antara actor dengan setiap fungsi pada sebuah system(Kadarisman \& Supriyono, 2019).Admin diberikan hak akses untuk mengelola data seperti tambah, ubah dan hapus pada buku koleksi, anggota, serta melakukan transaksi dan rekap data. Anggota perpustakaan hanya dapat melakukan

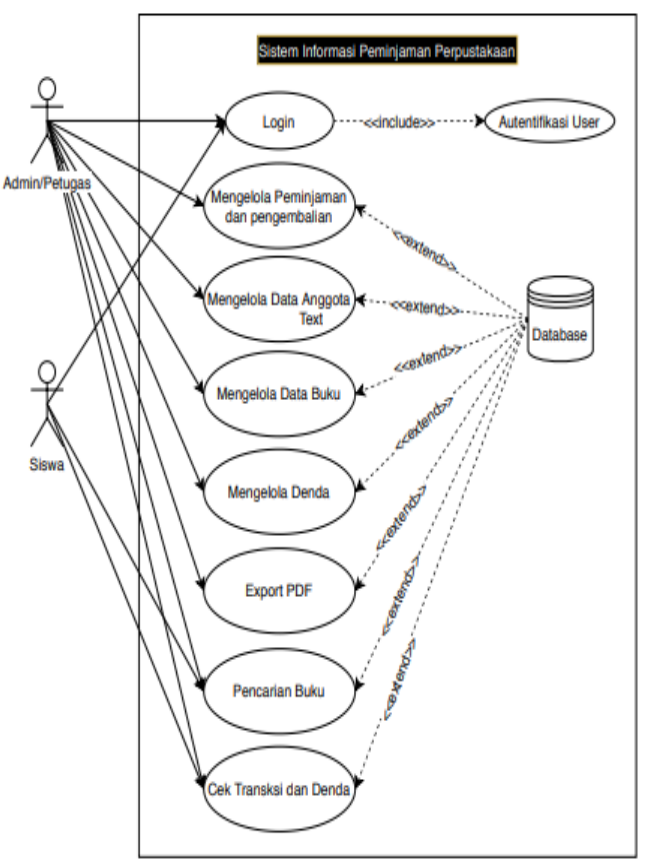

Gambar 3 Use Case Diagram Admin dan Anggota.

c. Activity diagram

Activity diagram merupakan
gambaran jalannya proses atau
merupakan penjelasan dari Use Case
yang telah di buat pada Gambar 3 yang
ebih jelasnya terdapat dalam Gambar 4
dan Gambar 5 .




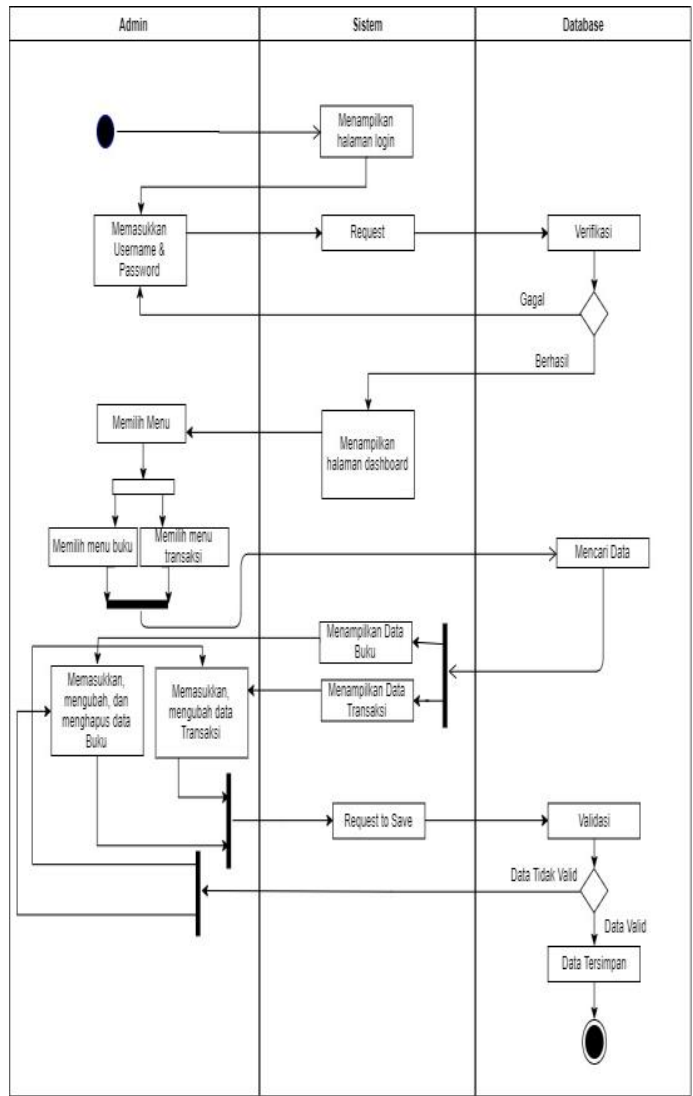

Gambar 4 Activity diagram Admin

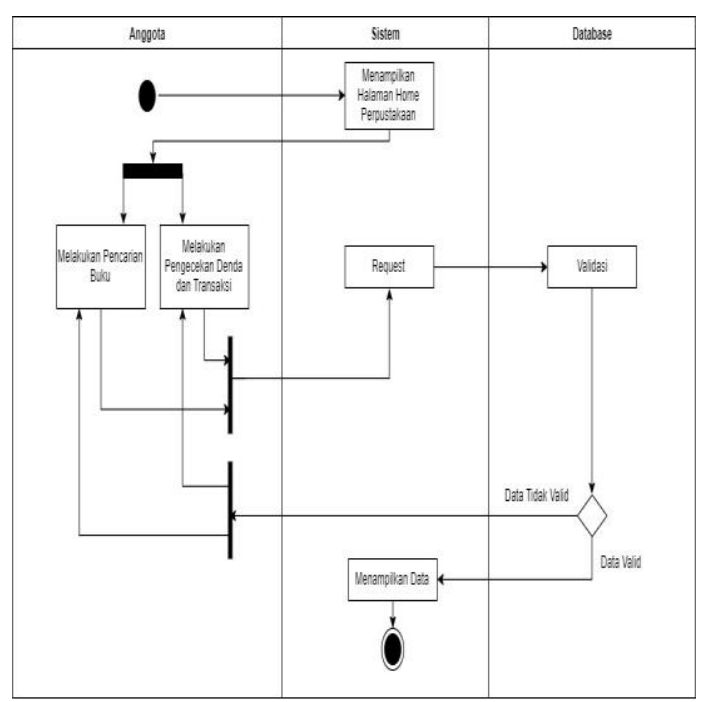

Gambar 5 Activity diagram Anggota

d. User Interface

User Interface merupakan tampilan yang dibuat untuk menggambarkan secara sederhana system yang akan di bangun. Tampilan yang akan dibahas dalam bab ini dilihat dari sisi User dan Admin.
1. Sisi Admin

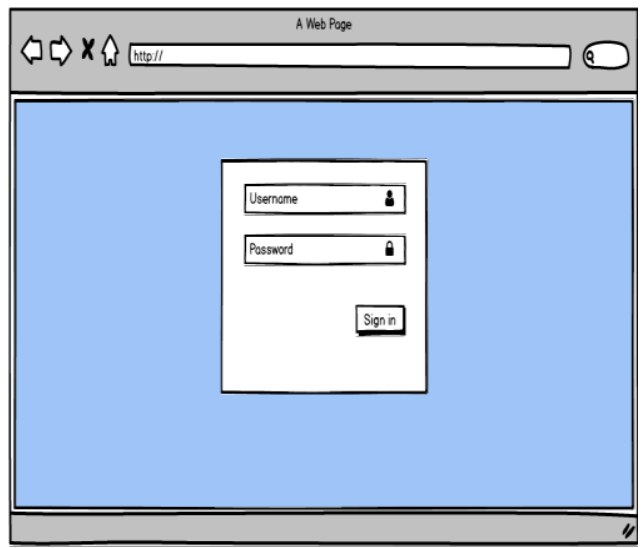

Gambar 6. Halaman Login Admin

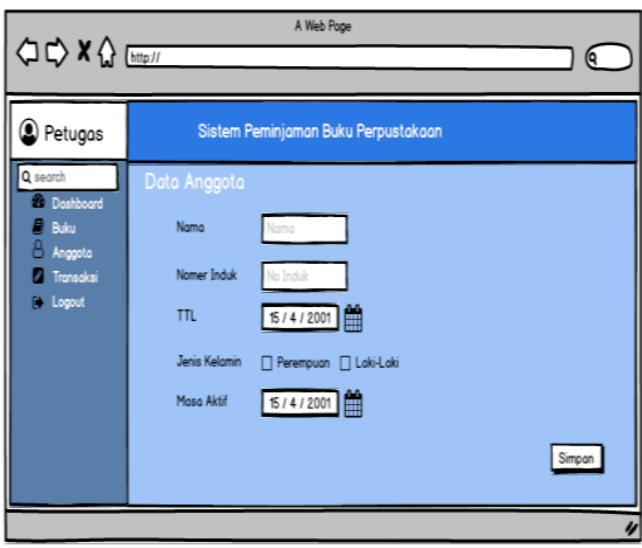

Gambar 7.Form Input Buku

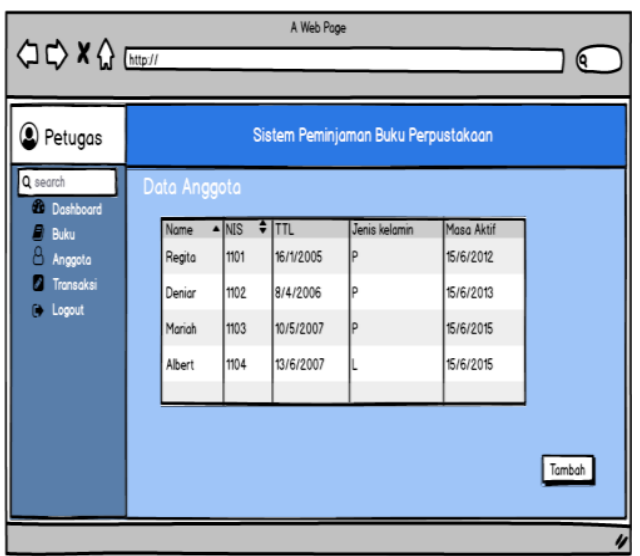

Gambar 8. Daftar Input Transaksi 
2. Sisi Anggota

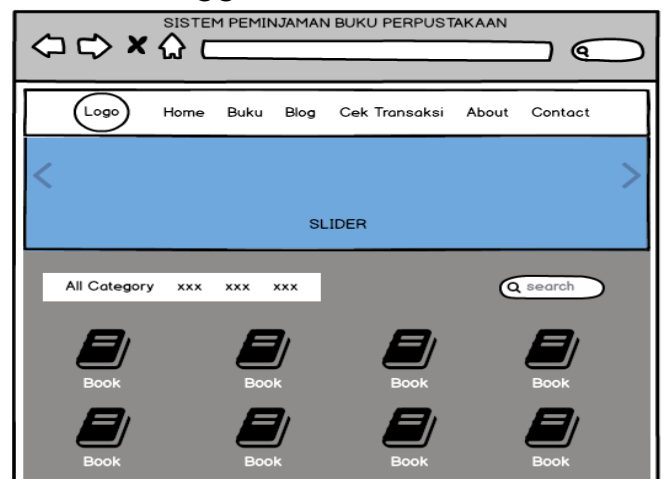

Gambar 9. Halaman Utama Anggota

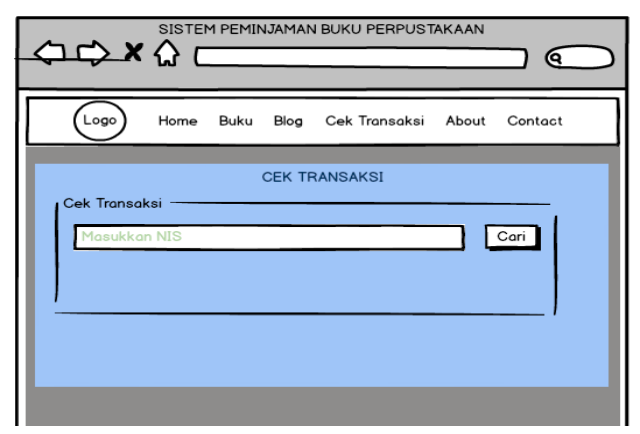

Gambar 10. Halaman Cek Transaksi

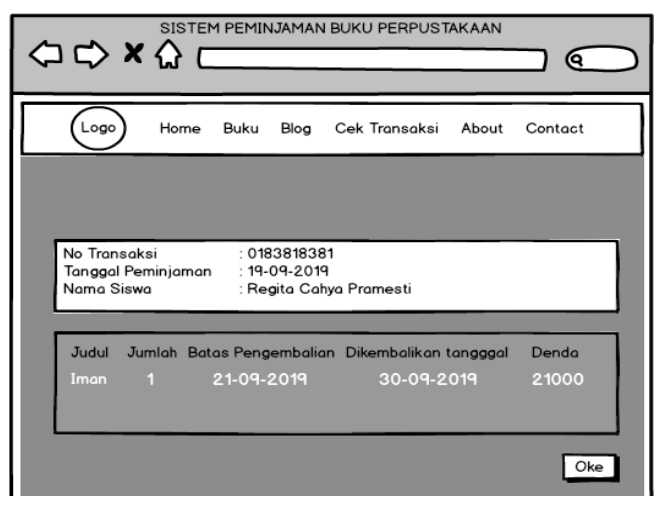

Gambar 11. Halaman Detail Cek Transaksi

\section{Coding/Pemrograman}

Tahap ini sistem dibuat menggunakan framework Bootstrap untuk tampilan front-end, kerangka kerja PHP codeigniter untuk proses backend. Dimulai dari membuat database sistem dilanjutkan dengan merubah tampilan dan coding php serta query MySQL.
4. Testing

Tahap testing menggunakan pengujain black box. Black box testing merupakan pengujian untuk mengetahui kelemahan dan kekurangan sistem secara langsung(Fitriyan, 2017).

\section{Implementasi}

Implementasi merupakan tahapan terakhir dari sebuah metode waterfall dimana dalam tahapan ini sistem yang telah dirancang dan dibangun telah siap digunakan atau diimplementasikan

\section{HASIL DAN PEMBAHASAN}

\subsection{Hasil}

Hasil pencapaian oleh peneliti setelah tahap pembangunan sistem yaitu menghasilkan sebuah Sistem Informasi Peminjaman Perpustakaan Berbasis Barcode. Sistem ini memiliki dua interface yang berbeda, yang membedakan antara petugas dan anggota perpustakaan. Hal tersebut menjadi alasan sistem ini memerlukan proses hosting agar dapat diakses secara online oleh siswa dan petugas. Proses hosting dimulai dengan membeli hosting dan domain di situs terpercaya. Kemudian file yang siap untuk dihostingkan diupload ke cPanel yang menjadi jembatan perintah-perintah teknis ke program-program pendukung website yang berada di web server.

\subsubsection{Halaman Login Admin}

Halaman login admin akan muncul setelah loading sistem. Admin atau petugas diminta untuk memasukkan username dan password agar mendapatkan hak akses untuk masuk kedalam sistem. Tampilan halaman login admin dapat dilihat pada Gambar 12. 


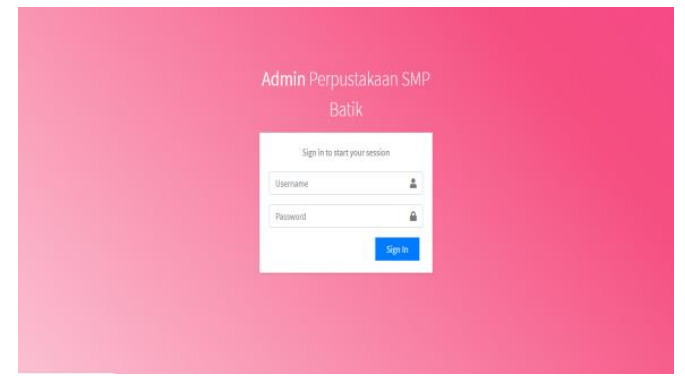

Gambar 12. Halaman Login Admin

\subsubsection{Halaman Dashboard \\ Halaman dashboard terdapat} tombol-tombol di bagian atas sebagai jalan pintas untuk membuka ke halaman formulir tambah data petugas, tambah data buku, tambah data anggota, dan jalan pintas untuk ke halaman data transaksi. Pada halaman dashboard juga terdapat formulir untuk manambahkan data transaksi baru yang akan dilakukan. Mengatur denda agar dinamis juga dilakukan dihalaman ini. Tampilan halaman dashboard dapat dilihat pada Gambar 13.

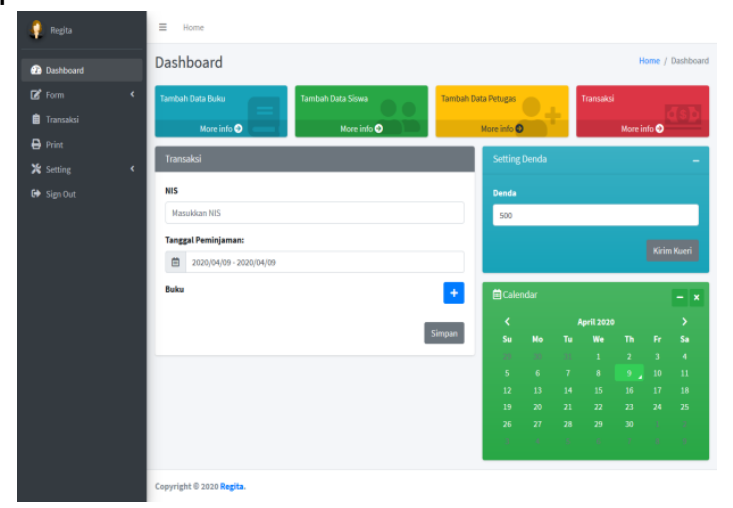

Gambar 13. Halaman Dashboard

\subsubsection{Halaman Form Anggota}

Halaman form anggota berisi data anggota yang terdaftar sebagai anggota perpustakaan. Pada halaman ini juga terdapat tombol tambah data yang akan mengarahkan user pada formulir tambah data anggota, tombol export ke excel yang berfungsi untuk mengeluarkan data anggota yang terdapat dalam database ke dalambentukfile .xls, serta tombol update digunakan untuk mengubah status anggota/siswa berdasarkan tanggal periode. Tampilan halaman form anggota secara detail dapat dilihat pada Gambar 14.

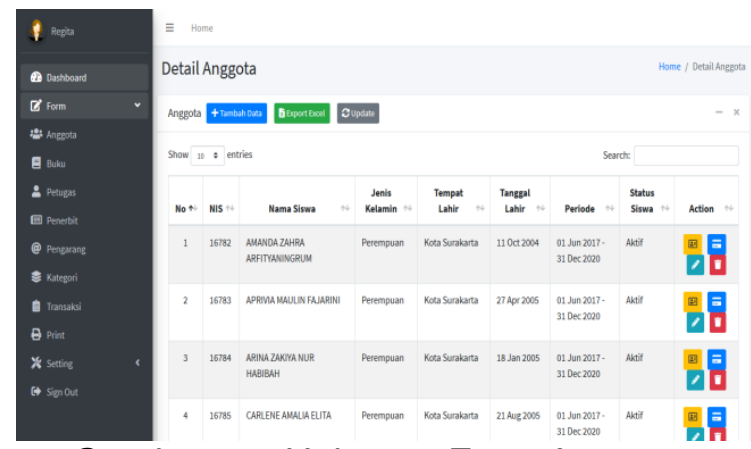

Gambar 14. Halaman Form Anggota

Pada tampilan halaman form anggota, terdapat tombol yang juga dapat digunakan untuk membuat kartu anggota dan kartu peminjaman anggota. Kartu yang dihasilkan dapat dilihat pada Gambar 15 dan Gambar 16.

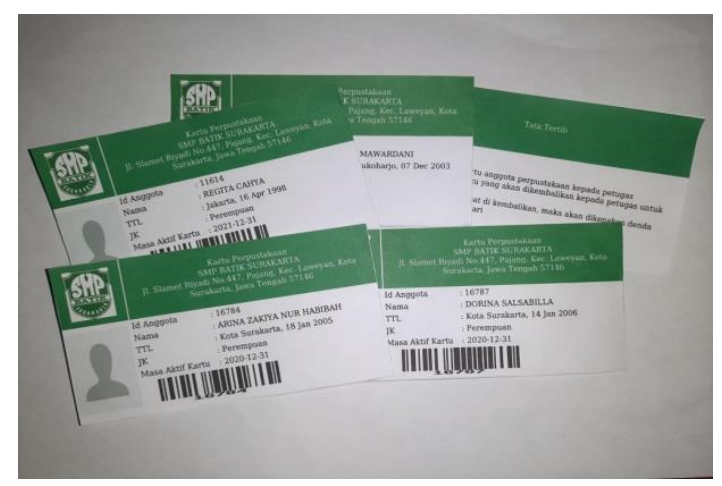

Gambar 15. Kartu Anggota

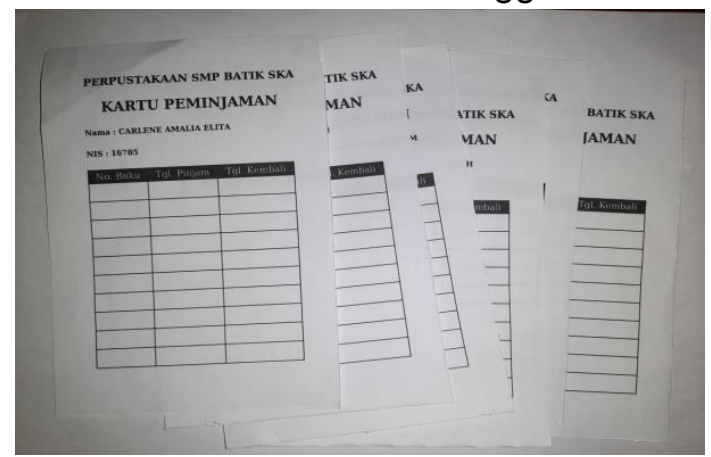

Gambar 16. Kartu Peminjaman

\subsubsection{Halaman Form Buku}

Halaman form buku berisi data buku yang dimiliki oleh perpustakaan. Pada halaman ini terdapat tombol tambah data yang akan mengarahkan user pada formulir tambah data buku baru, serta tombol export ke excel yang berfungsi 
untuk mengeluarkan data buku yang terdapat dalam database ke dalambentuk file .xls.Tampilan halaman buku dapat dilihat pada Gambar 17.

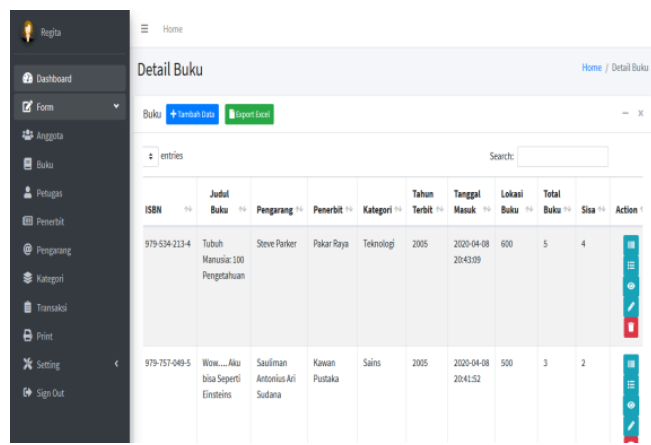

Gambar 17. Halaman Form Buku

Pada halaman ini terdapat tombol yang berfungsi untuk membuat katalog dan barcode setiap buku. Hasil dari katalog dan barcode buku dapat dilihat pada Gambar 18 dan Gambar 19.

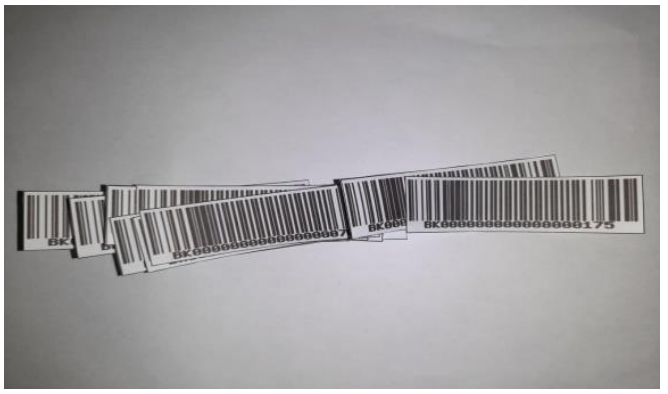

Gambar 18. Barcode Buku

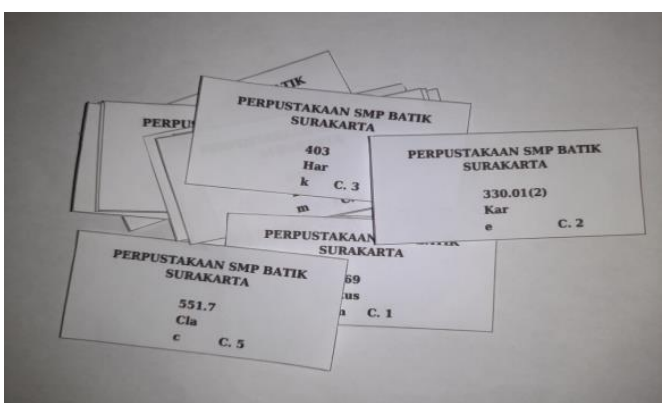

Gambar 19. Katalog Buku

\subsubsection{Halaman Transaksi}

Halaman transaksi menampilkan data transaksi yang pernah dilakukan. Selain itu, pada halaman ini petugas dapat mengubah batas tanggal kembali, menyelesaikan transaksi apabila buku sudah dikembalikan oleh siswa dan juga dapat terus meng-update perubahan denda setiap harinya pada transaksi yang melebihi batas pengembalian. Tampilan pada halaman ini dapat dilihat secara detail pada Gambar 20 dan Gambar 21.

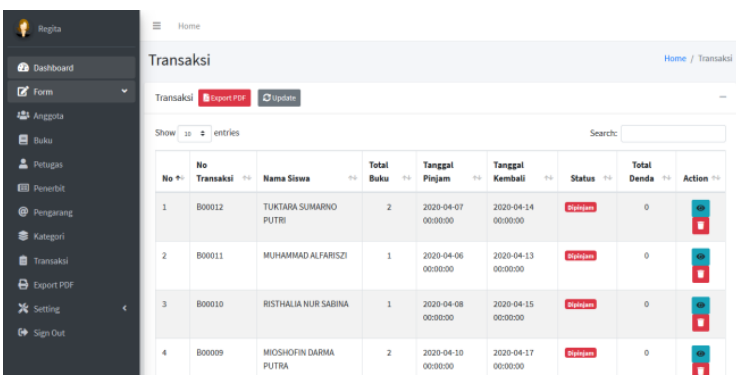

Gambar 20. Halaman Transaksi

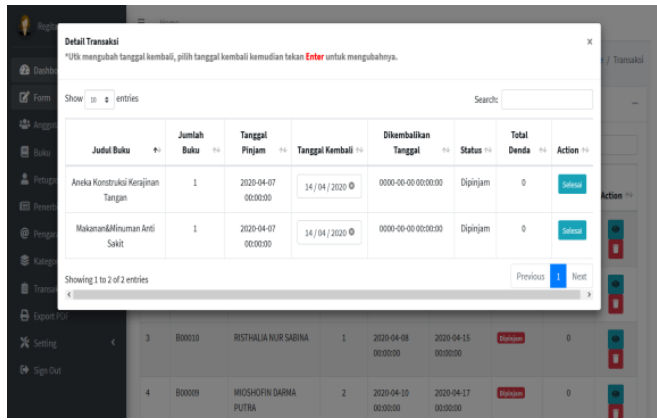

Gambar 21. Pop Up Detail Transaksi

\subsubsection{Halaman Export PDF dan Setting Halaman export pdf merupakan} halaman yang digunakan untuk mengeluarkan data dari dalam database kedalam bentuk file pdf. Data yang dapat diexport mengenai data siswa, buku, dan transaksi. Data tersebut dapat diexport berdasarkan filter yang diminta oleh petugas, yang kemudian hal tersebut akan dijadikan sebagai laporan untuk sekolahan. Tampilan halaman export pdf dapat dilihat pada Gambar 22. 


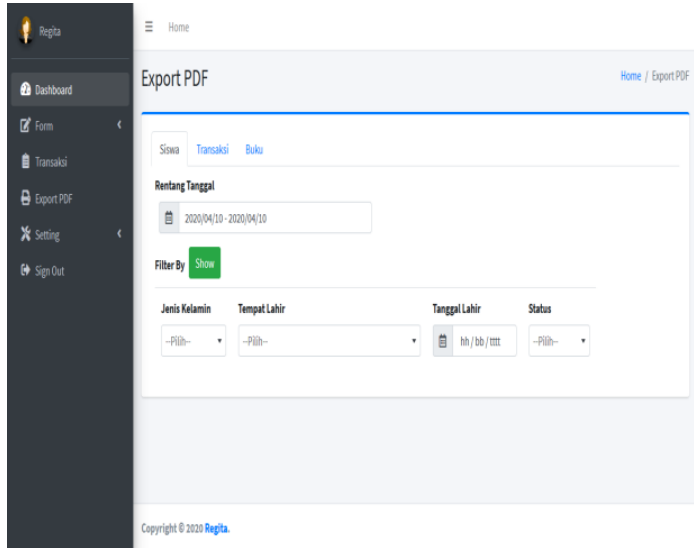

Gambar 22. Halaman Export PDF

Halaman setting merupakan halaman unuk mengubah data setting seperti tampilan untuk user, tampilan kartu anggota dan lain-lain. Tampilan halaman setting dapat dilihat pada Gambar 23.

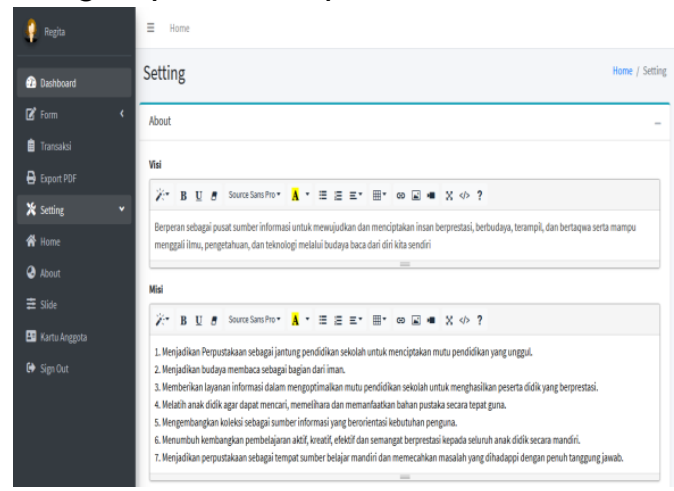

Gambar 23. Halaman Setting

\subsubsection{Halaman Utama User dan Halaman Katalog Buku}

Halaman utama user menampilkan slide dan tulisan yang berganti-ganti serta beberapa tampilan buku. Sedangkan pada katalog buku menampilkan keseluruhan buku yang dimiliki perpustakaan. Tampilan utama user dan katalog buku dapat dilihat pada Gambar 24 dan Gambar 25.

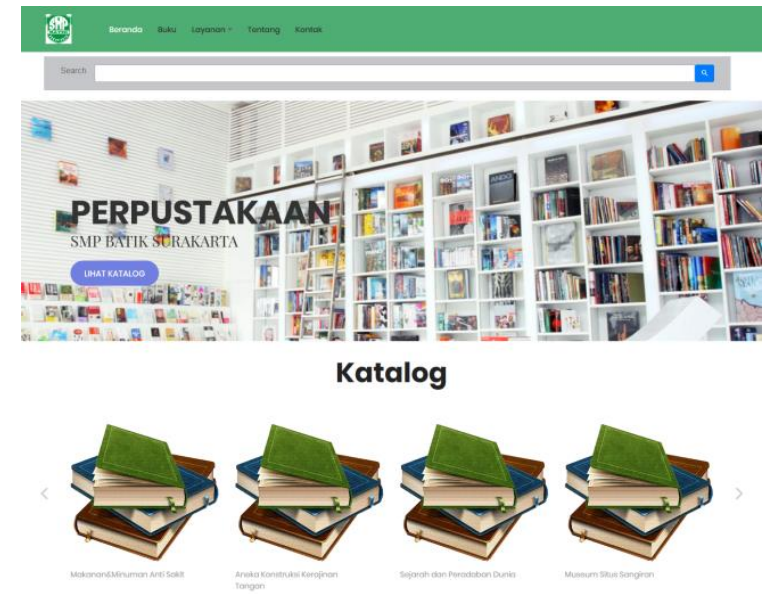

Gambar 24. Halaman Utama User

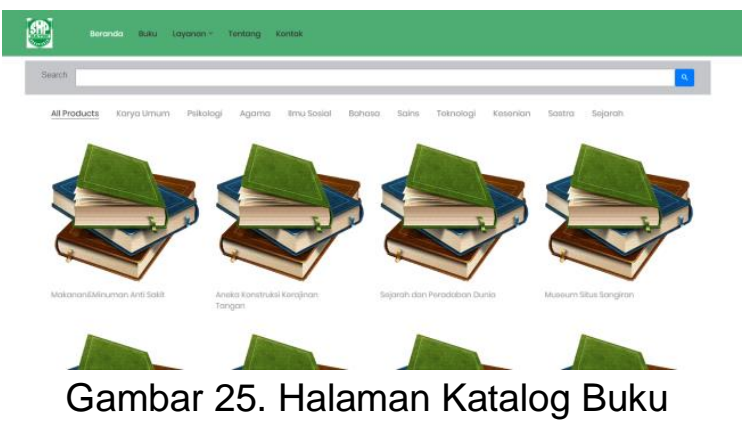

User dapat melihat informasi tentang penerbit, pengarang, kategori dan stok buku yang tersediasaat meng-klik tombol "Quick View", lalu sistem akan menampilkan pop up yang berisi detail buku seperti pada Gambar 26.

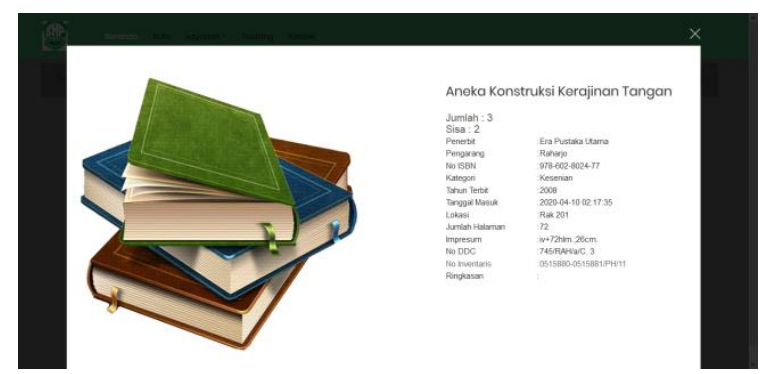

Gambar 26. Pop up Detail Buku

\subsubsection{Halaman Cek Transaksi}

Halaman cek transaksi digunakan untuk menampilkan data transaksi yang pernah dilakukan oleh siswa. Pertama, siswa diminta melakukan proses login untuk dapat mengakses halaman selanjutnya berupa data transaksi yang 
pernah dilakukan. Ketika proses login berhasil, maka siswa akan diarahkan ke halaman yang akan menampilkan total tagihan atas keterlambatan peminjaman seperti pada Gambar 27.

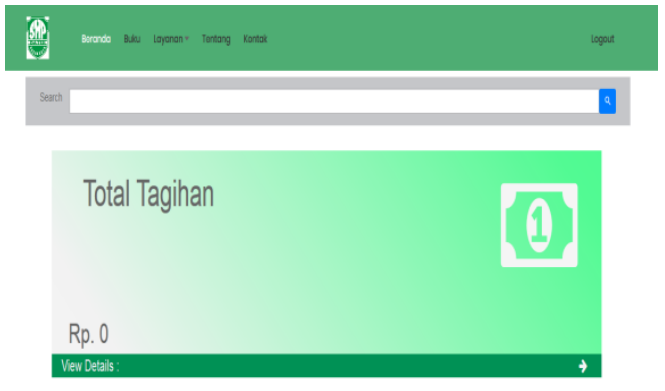

Gambar 27. Halaman Total Tagihan

Tombol "View Details" akan mengarahkan siswa pada data transaki yang dimaksud. Sistem akan menampilkan tampilan seperti pada Gambar 28.

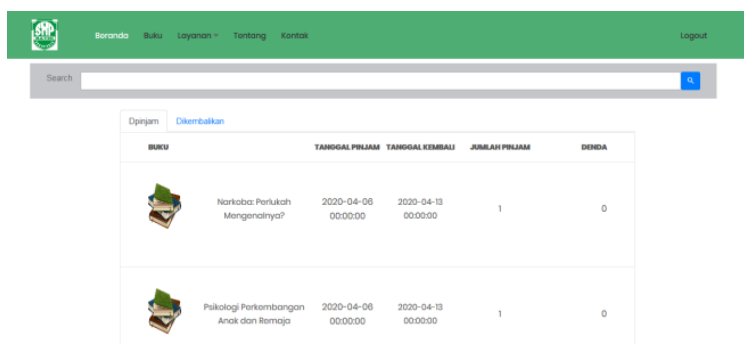

Gambar 28. Detail Transaksi

\subsection{Pembahasan}

Pengujian sistem ini memiliki tujuan untuk mengetahui apakah sistem bekerja dengan baik dan sesuai dengan apa yang telah direncanakan atau tidak. Pengujian ini menggunakan metode black-box testing untuk uji fungsionalitasnya, metode blackbox testing merupakan pengujian secara langsung untuk mengetahui kekurangan dan kelemahan sistem dengan penggunaan perangkat lunak dan fungsional sebagai titik fokusnya. Hasil dari pengujian black-box testing dapat dilihat pada Tabel 1.

\begin{tabular}{clcc}
\hline No & \multicolumn{1}{c}{ Input } & Output & Hasil \\
\hline 1 & $\begin{array}{l}\text { Petugas } \\
\text { memasukka }\end{array}$ & $\begin{array}{c}\text { Menampilka } \\
\text { n halaman }\end{array}$ & Valid
\end{tabular}

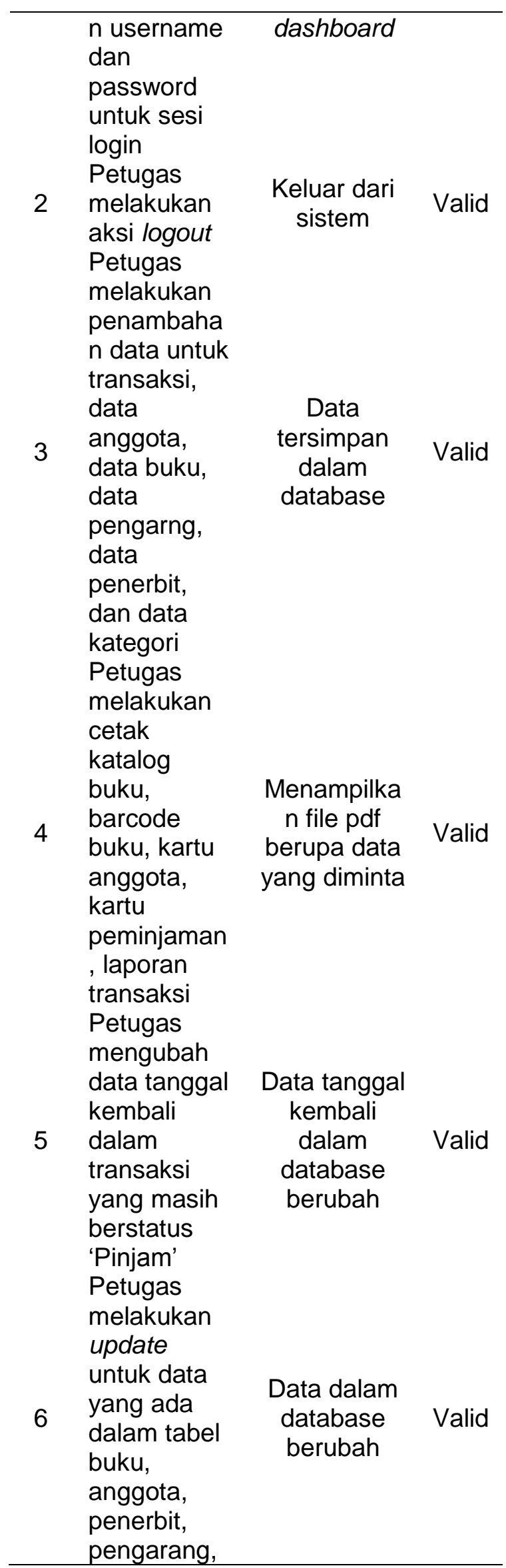




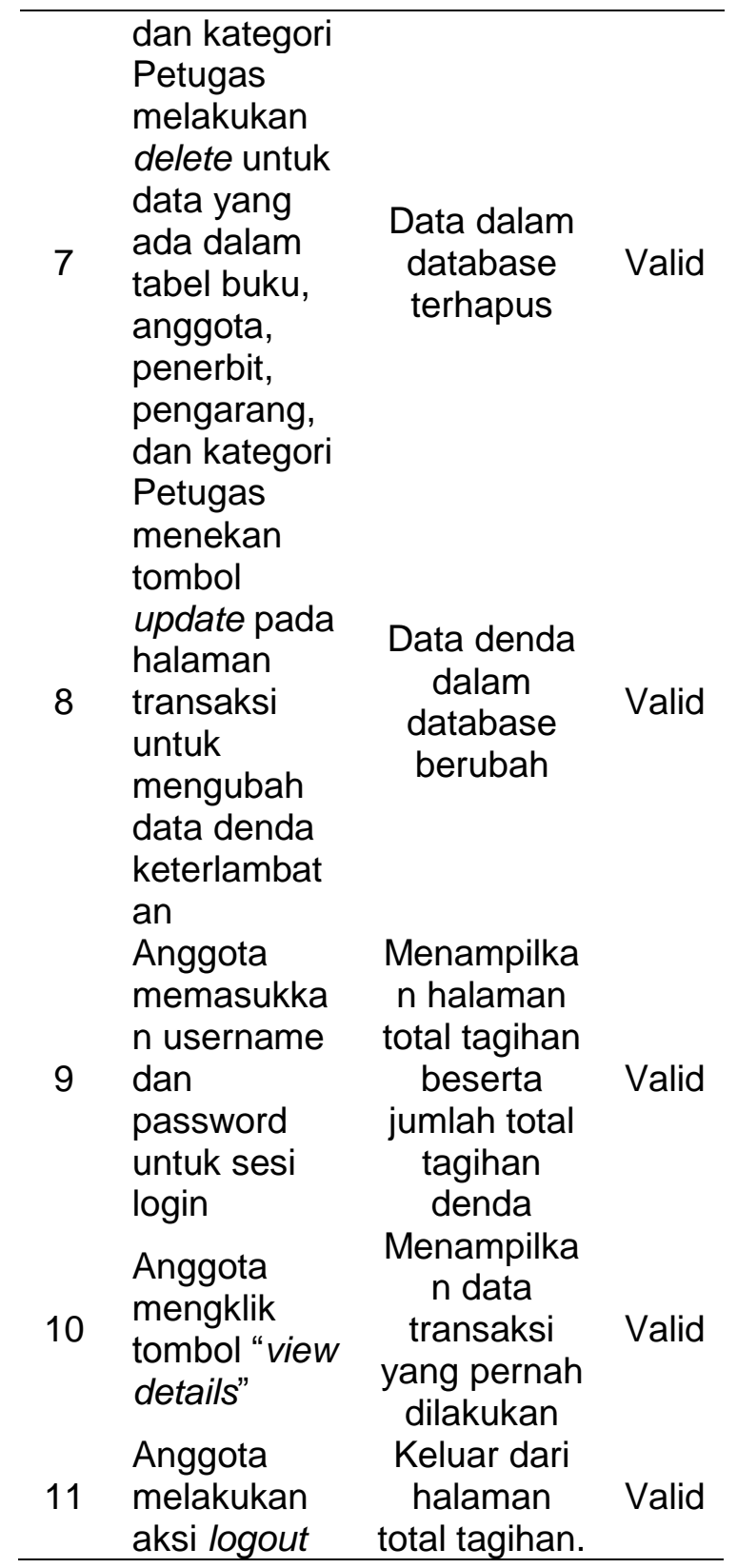

Berdasarkan hasil pengujian blackbox testing pada Tabel 1. Menunjukan hasil seperti yang diharapkan oleh peneliti, yaitu setiap aksi yang dilakukan baik dari petugas maupun siswa berjalan dengan baik.

\section{PENUTUP}

Berdasarkan hasil perancangan dan pembuatan sistem, serta pengujian pada sistem maka dapat disimpulkan bahwa Sistem Informasi Peminjaman Perpustakaan Berbasis Barcode dapat berjalan dengan baik. Saran untuk penelitian selanjutnya yaitu, dapat menambahkan fitur peminjaman secara online untuk menciptakan sistem yang lebih baik.

\section{DAFTAR PUSTAKA}

Benmoussa, K., Laaziri, M., Khoulji, S., Larbi, K. M., \& El Yamami, A. (2019). A new model for the selection of web development frameworks: application to PHP frameworks. International Journal of Electrical and Computer Engineering (IJECE), 9(1), 695. https://doi.org/10.11591/ijece.v9i1.pp6 95-703

Choiyanti, F., Latifah, N., \& Triyanto, W. A. (2020). Web Utilization and Telegram Gateway Features for Management of Booking Make Up Services at Ulfisinta Make Up Web Utilization and Telegram Gateway Features for Management of Booking Make Up Services at Ulfisinta Make Up. Journal of Physics: Conference Series, 1430, 0-9. https://doi.org/10.1088/17426596/1430/1/012051

Febi Andrea Renatha, Kodrat Iman Satoto, O. D. N. (2015). Perancangan dan Pengembangan Sistem Informasi Perpustakaan Berbasis Web(Studi Kasus Jurusan Sistem Komputer). Jurnal Teknologi Dan Sistem Komputer, 12(1), 343-353. https://doi.org/10.1186/s13023-0170672-7

Firman, A., Wowor, H., \& Najoan, X. (2016). Sistem Informasi Perpustakaan Online Berbasis Web. Jurnal Sistem Informasi Bisnis, 1(2), 66-77.

https://doi.org/10.21456/vol1 iss2pp6972

Fitriyan, M. R. (2017). Sistem Informasi pengelolaan perpustakaan berbasis QRCODE. 1-15.

Hendrianto, D. E. (2014). Pembuatan Sistem Informasi Perpustakaan Berbasis Website Pada Sekolah Menegah Pertama Negeri 1 Donorojo 
Kabupaten Pacitan. IJNS-Indonesian Journal on Networking and Security ISSN: 2302-5700 (Print) 2354-6654 (Online, 3(4), 2354-6654.

Heriyanto, B. D., Kurniawan, I. A., \& Taufik, I. (2017). Sistem Aplikasi Perpustakaan Berbasis Web Menggunakan Framework Codeigniter pada SMAS Islamic Centre. Jurnal IImiah Sisfotenika, 7(2), 187. https://doi.org/10.30700/jst.v7i2.147

Kadarisman, E. P., \& Supriyono, H. (2019). Sistem Penampil Informasi Koleksi Batik Berbasis Qr Code Di Gedung Seminar Siti Walidah Muhammadiyah Surakarta. Jurnal IImiah SINUS, 17(1), 37.

https://doi.org/10.30646/sinus.v17i1.3 94

Kurniasih, N., Kurniawati, N., Sujito, Rizal, E., Sudirman, A., Mesran, ... Satria, E. (2019). Analysis of the implementation of Unpad Library Management System using the Technology Acceptance Model: Librarian perspective. Journal of Physics: Conference Series, 1175(1). https://doi.org/10.1088/17426596/1175/1/012228

Malau, E., Salim, A., Santoso, B., \& Ramadan, R. (2018). Sistem Informasi Manajemen Perpustakaan Dengan Barcode Di GKI Gunung Sahari Jakarta. Bina Insani Ict Journal, 5(1), 41-50. Retrieved from https://repository.bsi.ac.id/index.php/u nduh/item/113186/868-97-2119-1-1020180722.pdf

Okolo, S. E., Eserada, R. E., Ugboh, P. N., \& Ngbo, D. L. (2019). Collections and collection development exercise in libraries: A perspective in view. Library Philosophy and Practice, 2019(January).

Pratiwi, D., Hartini, S., \& Marlina, S. (2018). Rancang Bangun Sistem Informasi Perpustakaan Pada Sekolah SMK Yadika 13 Tambun Utara Berbasis Web. Paradigma, XX(1), 53-58.

Puspaningrum, A., \& Sudarmilah, E. (2020). Sistem Informasi Manajemen Peminjaman ( Studi Kasus: Pengelolaan Aset Dan Tata Ruang
Taman Budaya Jawa Tengah ). Technologia: Jurnal IImiah, 11(1), 3745.

Putera, A. R., \& Ibrahim, M. (2018). Rancang Bangun Sistem Informasi Peminjaman dan Pengembalian Buku Perpustakaan SMP Negeri 1 Madiun. DOUBLECLICK: Journal of Computer and Information Technology, 1(2), 57. https://doi.org/10.25273/doubleclick.v1 i2.2025

Rahaman, W. (2016). Enhancin Library Services Using Barcode, QR Code and RFID Technology: a Case Study in Central Library National Institute of Technology, Rourkela. International Journal of Digital Library Services, 6(3), 39-50.

Ridha, M. R. (2017). Analisa Dan Desain Model Sistem Informasi Perpustakaan Universitas Islam Indragiri. Jurnal SISTEMASI, 6(September), 23-33.

Rita Irviani, R. O. (2017). Aplikasi Perpustakaan Pada SMA N1 Kelumbayan Barat Menggunakan Visual Basic. Jurnal TAM ( Technology Acceptance Model ), 8(1), 63-69.

Sukrianto, D., \& Oktarina, D. (2017). Pemanfaatan teknologi barcode pada sistem informasi perpustakaan di smk muhammadiyah 3 pekanbaru. JOISIE Journal Of Information System And Informatics Engineering, 1(2), 136143.

Wiharto, Y. (2016). Perancangan Sistem Perpustakaan Menggunakan Model View Controller (Mvc) Dengan Metode Object Modelling Technique (Omt) Pada Sekolah Menengah Pertama Negeri 44 Palembang. Jurnal Teknik Informatika, 10(2), 147-158. https://doi.org/10.15408/jti.v10i2.6993

Zhang, J. (2019). Talking about the Characteristics of Subject Service in University Library. Atlantis Press, 75(ICEM 2018), 116-119. https://doi.org/10.2991/icem18.2019.31 